\title{
Scenario analysis of source management practices: Impact on sewerage networks
}

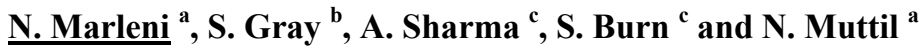 \\ ${ }^{a}$ School of Engineering and Science, Victoria University, PO Box 14428, Melbourne, VIC 8001, Australia \\ ${ }^{b}$ Institute for Sustainability and Innovation, Victoria University, PO Box 14428, Melbourne, VIC 8001, \\ Australia \\ ${ }^{c}$ CSIRO Land and Water, (PO Box 56), 37 Graham Road, Highett, VIC 3190, Australia \\ Email: nepi.ninyoman@live.vu.edu.au
}

\begin{abstract}
Developments in urban areas increasingly consider the sustainability of water and wastewater management in their planning. One aspect of sustainability refers to the condition where water supply is sourced locally and wastewater discharges are utilized locally as alternative resources on a fit for purpose basis. Source management practices (SMPs) such as demand management, greywater reuse, rainwater use and sewer mining offer benefits of water saving and wastewater reduction. While the positive effects of SMPs have been widely acknowledged, the implementation of SMPs is also likely to alter the wastewater quality and flow characteristics. These alterations might affect downstream sewerage networks and wastewater treatment plants. SMPs tend to lower the wastewater flow, which subsequently increases the concentration of contaminants. Lower flow and higher contaminant concentration lead to increases in sewer problems such as blockages, odour and corrosion. Sewer blockages due to these SMP have been assessed in a few studies, whereas impacts of SMPs on odour and corrosion have not yet been investigated. The problems of odour and corrosion are frequently observed in sewerage networks, especially in areas with warm climate. These problems are caused by hydrogen sulphide $\left(\mathrm{H}_{2} \mathrm{~S}\right)$ that is released into the sewer atmosphere. $\mathrm{H}_{2} \mathrm{~S}$ formation in sewers is dependent on the wastewater quality and flow characteristics.
\end{abstract}

This paper analyses a range of scenarios that represent different SMPs in terms of their impact on flow characteristics and wastewater quality that indicate their contribution to odour and corrosion problems in sewerage networks, by using an urban water balance model. The Urban Volume and Quality (UVQ) model is used to simulate the volume of water and wastewater flow and the associated wastewater quality parameters from different scenarios. UVQ is capable to estimate the water/wastewater quality parameters loads and the water/wastewater flows their source to the discharge point.

Six scenarios are selected for evaluation, which are as follows:

i) Base case - Estimation of a conventional household based on monitoring data and literature.

ii) High water demand management - Simulates uptake of highest water efficient appliances.

iii) Greywater recycling (direct diversion) - Greywater (bathroom and laundry) is directed to garden irrigation.

iv) Greywater recycling (treatment and storage) - Greywater (bathroom and laundry) is treated and stored for use in flushing toilet.

v) Rainwater harvesting - Roof run-off captured for toilet flushing.

vi) Sewer Mining - Extracts wastewater from major sewerage pipe, which is then treated and used for toilet flushing.

The wastewater parameters investigated were those which caused the problems of odour and corrosion in sewerage networks. These parameters are: chemical oxygen demand (COD), nitrate $\left(\mathrm{NO}_{3}{ }^{-}\right)$, sulphate $\left(\mathrm{SO}_{4}{ }^{2-}\right)$, iron $(\mathrm{Fe})$, copper $(\mathrm{Cu})$, zinc $(\mathrm{Zn})$ and total suspended solid (TSS).

The results of the scenario simulations provided an approximation of the impact of different SMPs on domestic wastewater quality and flow characteristic. Eventually, these analyses will help to quantify the impact of SMPs on odour and corrosion problem in sewerage pipe networks.

Keywords: Sewerage networks, source management practices, greywater recycling, high water demand management, rainwater harvesting, sewer mining 


\section{INTRODUCTION}

Development in urban areas increasingly considers the sustainability of local water and wastewater management. Source control management or source management practices (SMPs) include water demand management, rainwater harvesting, greywater recycling, and sewer mining. The major advantages of SMPs such as saving potable water, and reducing the environmental impact of discharged wastewater to the environment (Radcliffe 2010). However, the implementation of SMPs is predicted able to alter wastewater characteristics which can affect the performance of downstream infrastructure such as sewerage networks. Studies from Cook et al. (2010) and Parkinson et al. (2005) have revealed that many SMPs produced higher strength sewage and lower discharge volumes. These changes might affect the extent of solid's deposition and biochemical transformations in sewer networks, thus leading to sewer degradation, particularly via blockages, odour and corrosion.

This paper analyses a range of scenarios that represent different SMPs in terms of their impact on wastewater flow and contaminant that indicate their contribution to odour and corrosion problems in sewerage networks by using an urban water balance model. The Urban Volume and Quality (UVQ) model is used to simulate the volume of water and wastewater flow and associated contaminant from different scenarios, details of UVQ is discussed in Section 5.1. To analyze the potential impact of SMPs on sewer, the wastewater flow and some contaminants were selected according to their tendency to cause problems of odour and corrosion in sewer networks. These contaminants are organic and solid compound (COD and TSS), sulphate, nitrate and metals (iron, copper and zinc). The selections of these contaminants are discussed in Section 2. The explanation of the six scenarios is described in Section 4. Section 6 of this paper presents details of setting up the base case and Section 7 presents the results and comparison of all six scenarios. Finally, discussion and conclusions drawn from the study are presented in Section 8.

\section{SELECTED WASTEWATER CONTAMINANT \& ASSOCIATED SEWER PROBLEM}

The sewer problem of odour and corrosion are mostly occurred due to hydrogen sulphide gas. The formation of sulphide gas is triggered by some factors include moderate to high temperature, low $\mathrm{pH}$, wastewater contaminant such as sulphate and organics, and less wastewater flow. In this study, the discussion is emphasized on the wastewater contaminants from each of SMPs which are likely to trigger/increase or to decrease the sulphide gas formation in sewerage networks. Because according to Zhang et al. (2008) wastewater contaminant control can be done through source control technologies or SMPs.

There are several wastewater contaminants and parameter that trigger the sulphide odour and corrosion problem, they are sulfate, organics (represented as COD), solid (represented as TSS) and wastewater flow. Sulfate and Organic matter are used in the processes of sulphide formation through sulfur and carbon cycle. Solid in wastewater mostly contains organics matter which makes the solids has cohesive characteristics. Cohesive solids tend to form sediment in which the biological sulfide formation processes mainly occur in this sewer part. Wastewater flow is important parameter which determines the wastewater velocity and reaeration process. Nitrate and metal content are known for the parameters that eliminating sulphide emission. These chemical are usually added to the wastewater in certain amount of concentration. These chemical naturally exist in wastewater but in low concentration. Nitrate exists in residential wastewater with concentration around $1 \mathrm{mg} / \mathrm{L}$. Metal such as Iron, copper and zinc are added to the wastewater and react with dissolve sulphide to form metal salts that will precipitate and reduce the chance of sulphide gas emission. The concentration of iron in domestic wastewater is around 0.4-1.5 mg/L (Nielsen et al. 2005).

Therefore it can be concluded that the increasing concentration of organic, sulphate and solids in wastewater indicate the increasing risk of odour and corrosion problem. This condition is worsened if less wastewater flow is discharged to sewerage network. In contrast, the increasing concentration of nitrate and metal content such iron, copper and zinc is decreasing the risk of odour and corrosion problem.

\section{CASE STUDY}

The chosen case study is Glenroy branch subcatchment is located in the Pascoe Vale catchment in northern Melbourne. This subcatchment mainly consists of residential landblock with only few small industries, school and commercial precincts. However, in this study, it was assumed that all the sewer connections are originated from residential landblocks. In total, the catchment size of the Glenroy branch has about 3750 sewer connections (YVW 2010). However, since the wastewater sample was taken in the middle part of sewer pipe then only 2610 connections are considered to be landblock in the model simulation. 
In the study area of $425 \mathrm{Ha}$, a typical residential size block was assumed to be in the range of $125-790 \mathrm{~m}^{2}$, comprising a roof area of $63-467 \mathrm{~m}^{2}$, garden area of $43-274 \mathrm{~m}^{2}$ and it was assumed that all the landblock have a paved area of $50 \mathrm{~m}^{2}$. The road area in the study area was calculated at $41.6 \mathrm{Ha}$ and open space area was $271 \mathrm{Ha}$. According to a study by Roberts (2005), the average household size in Yarra Valley Water's service area is 2.55 people. This is assumed as the value of occupancy rate for the studied area. The existing sustainable practices which have been implemented in Glenroy sewer subcatchment are rainwater harvesting and greywater recycling. According to YVW (2010)'s information, around 30\% of the residential landblock in this area has rainwater tank but only $3 \%$ used the collected rainwater for toilet/laundry purpose. For greywater recycling, only $3 \%$ of the landblocks have the greywater recycling facilities.

\section{SCENARIO OVERVIEW}

\subsection{Base Case}

The base case scenario represents the condition where usual/normal water demand management has been implemented. There are 30\% household installed rainwater tanks and 3\% of them use rainwater tank for toilet or laundry as well as 3\% of household have greywater recycling facilities. Most of household water demands are supplied from imported potable water. The wastewater produced within the household will be discharged directly to the sewer pipe network. Details about setting up of the base case are presented later in Section 5.

\subsection{High Water Demand Management}

High water demand management simulates uptake of high water efficient appliances. The assumption used in this scenario is that for each end use, the contaminant loads are similar to the base case. The only difference is in the reduced indoor water usage. The water efficiency assumption for each appliance is based on Australian Government Water Efficiency Labeling and Standards (WELS) scheme (Australian Government 2010b), as presented below :

Toilet - Full flush $\rightarrow 4.2$ litres; half flush $\rightarrow 2.7$ litres; average flush volume : 3 litres (WELS Rating 5).

Washing machine (8 kilogram capacity) $\rightarrow$ average volume per wash : 57 litres (WELS rating 5).

Dishwasher $\rightarrow$ average volume per wash : 11.1 litres (WELS rating 5).

Shower $\rightarrow$ Flow rate : 6 litres per minute (WELS rating 3).

Taps (bathroom, kitchen and laundry sinks) $\rightarrow$ Flow rate : 4.5 litres per minute (WELS rating 5).

\subsection{Greywater Reuse (direct diversion)}

Laundry and bathroom greywater is directly directed to subsurface garden irrigation from individual household without any treatment process. It was assumed that $30 \%$ garden was irrigated. The value of total garden area is obtained from the GIS map of pervious and impervious area of the selected case study site.

\subsection{Greywater Recycling (treatment and storage)}

Greywater from bathroom and laundry was treated and supplied for toilet flushing and garden irrigation. According to Surendran \& Wheatley (1998), greywater storage tanks for home use vary from $0.5 \mathrm{~m}^{3}$ to 30 $\mathrm{m}^{3}$. It was assumed in this scenario that the storage tank had a capacity of $1 \mathrm{~m}^{3}$ and that it was $50 \%$ full at the start of the simulation. Excess greywater is directed to sewer system. The removal efficiency from greywater treatment is found in Tchobanoglous et al. (2003).

\subsection{Rainwater Harvesting}

The rainwater harvesting scenario assumes that the storage capacity is $4 \mathrm{~m}^{3}$ which is within the range of $2-$ $10 \mathrm{~m}^{3}$ for rainwater tanks installed in Australian homes (Australian Government 2010a). The first flush volume for $200 \mathrm{~m}^{2}$ average roof size is $0.025 \mathrm{~m}^{3}$. In this scenario, the rainwater was used for toilet flushing.

\subsection{Sewer Mining}

Sewer Mining extracts wastewater from major sewerage pipes, which is then treated and used as toilet flushing. The remaining solids are immediately returned to the sewer for treatment at a sewage treatment plant. In UVQ, the sewer mining is simulated by assuming that the study area wastewater treatment is installed and the treated wastewater is used for toilet flushing. The storage tank capacity of the treated wastewater is set to $500 \mathrm{~m}^{3}$. The contaminant load that discharges to the sewer pipe network is obtained from the summation of wastewater contaminant from the spillage and sludge production. A membrane bioreactor was selected as the sewer mining treatment process and the removal efficiency was found from Tchobanoglous et al. (2003). 


\section{METHODOLOGY}

\subsection{Urban Volume and Quality (UVQ)}

UVQ is an urban water balance and contaminant balance analysis tool that is able to analyse the flow paths and contaminants concentration or load from source to discharge point through an urban area. UVQ is also a tool to investigate the impact on flow and contaminant concentration or load from conventional and non conventional practices. A key feature of UVQ is the integration of stormwater, drinking water supply and wastewater systems into a single framework that enables a holistic view of the urban water system (Mitchell \& Diaper 2005). In the UVQ representation, imported water supplies and rainwater are the major inflows to the urban water cycle; while wastewater, stormwater and evaporation are the main outflows. Water sources can be used for indoor and outdoor end-uses. UVQ has a three-level hierarchy to represent the different spatial scales of an urban area; these are the land block, neighbourhood and the study area. The land block represents a single dwelling or other building type, while a neighbourhood is an aggregation of land blocks that have identical characteristics (Mitchell \& Diaper 2005).

In UVQ model, the water balance and contaminant balance operations occur sequentially for each daily time step with the model output summed to monthly and annual totals. The water balance program loop calculates the flows through the urban water system. The contaminant balance operations are based on the water volumes calculated in the water balance and user specified concentrations, loads and performance criteria. UVQ uses model simplification approach where all the contaminants are all modelled conservatively, with no conversion or degradation within the existing infrastructure and with simple mixing and removal processes as the basis for calculations and do not consider temporal variations in water quality.

\subsection{Assumption Used}

A number of assumptions are used in the UVQ model simulation, which are listed below :

* Since the only $3 \%$ of household use the rainwater for toilet/laundry purpose, hence $97 \%$ of household was assumed to use the rainwater for garden purpose.

* It was assumed that only greywater from bathroom and laundry are diverted into greywater recycling plant and the reclaimed water was used for toilet and gardening purpose.

* Leakage from water mains was assumed to be $4 \%$ of water losses.

\subsection{Data Input}

This section describes the various parameters that were input to the UVQ model for setting up the base case.

\subsubsection{Contaminant Inputs}

The contaminant inputs of UVQ are comprised of several input items, but for this study, only three contaminant inputs are important, which are: Drinking Water Supply (Imported water), Indoor use and the roof runoff from rainfall.

\section{* Rainfall}

The climate files used for this study were daily rainfall values from the Essendon station, available for download from the Bureau of Meteorology website. The data covers from 2003 to 2010 (see Figure 1). Seven years duration has been selected because the water restriction and practices of potable water substitution with alternatives water are more stringent and boomed after prolonged drought on 2002. The contaminant data for rainfall and roof runoff are obtained from the studies of Coombes et al. (2002) and Yaziz et al. (1989), which are presented in Table 1.

\section{* Drinking Water Supply (Imported water)}

The imported water contaminant data was obtained by assuming that all the contaminant parameters are in the range of Australian Drinking Water Guidelines (ADWG). The parameter values from ADWG standard that were used in this study can be seen in Table 1.

\section{* Indoor use}

The water contaminant is taken as a load per person per day in UVQ. In this study the load is obtained from the concentration multiplied by the average water consumption. A literature review on blackwater has been reported by Almeida et al. (1999), where they have explained the proportion of contaminants derived from faeces, urine, faeces + urine and toilet paper (Table 1). A worldwide review by Eriksson et al. (2002) which contains results from former greywater studies is used in this study. Metal contaminant load was taken from the study conducted by Cook et al. (2010) (Table 1). 


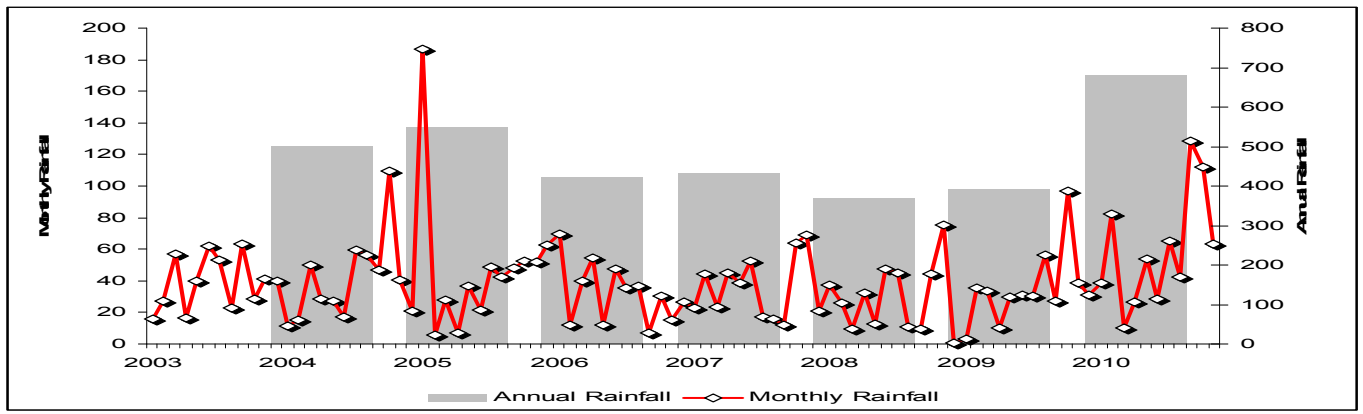

Figure 1. Monthly and Annual Rainfall from 2003-2010

Table 1. The contaminant load from imported water, blackwater and greywater, rainfall and roof runoff

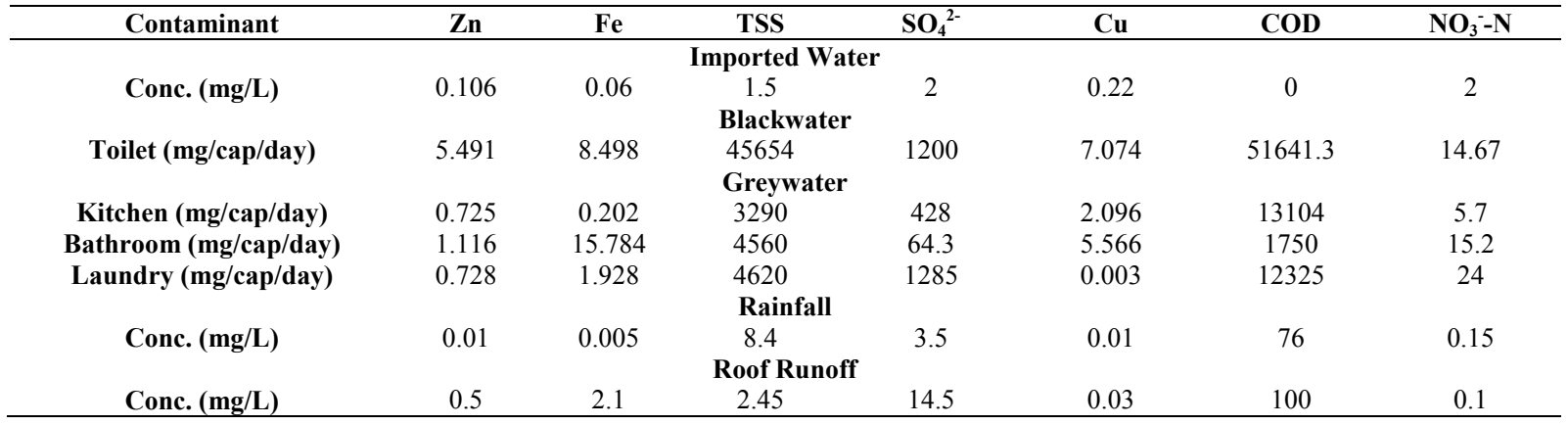

\subsubsection{Water Consumption}

In UVQ there are four indoor uses are listed: toilet, bathroom, laundry and kitchen. Average daily per capita use was computed based on the use frequency of the appliances, water consumption per use and also the number of household occupant. These data was obtained from Roberts (2005). From the computation, a dweller of the studied area consumes is 164 liters of water. The breakdown of this number is below :

Toilet: $31.9 \mathrm{~L} / \mathrm{cap} /$ day Laundry: $47.9 \mathrm{~L} / \mathrm{cap} /$ day Kitchen: $12.3 \mathrm{~L} / \mathrm{cap} /$ day Bathroom: $71.9 \mathrm{~L} / \mathrm{cap} / \mathrm{day}$

\section{CALIBRATION}

The wastewater generation in UVQ consist of six sub processes; they are wastewater discharge, wastewater exfiltration, overflow, infiltration, inflow and septic disposal. The model parameters for the wastewater generation are the infiltration and exfiltration ratio, infiltration store recession constant, percentage surface runoff as inflow, dry and wet weather overflow rate. When calibrating the UVQ, the model parameters, was changed by trial and error until the wastewater flow from the study area produced from the UVQ model within the range of $\max$ and min and nearly equalled to the observed wastewater flow and contaminant concentration (see Table 2).

Table 2. Comparison between the Observed and Simulated Value

\begin{tabular}{lcccc}
\hline \multirow{2}{*}{\multicolumn{1}{c}{ Wastewater Parameter }} & \multicolumn{3}{c}{ Observed } & \multirow{2}{*}{ Simulated } \\
\cline { 2 - 4 } & Max & Min & Average & \\
\hline Flow (Ml/year) & 4352 & 95 & 772 & 410 \\
COD (mg/L) & 1226 & 160 & 380 & 527 \\
Nitrate (mg/L) & 3.38 & 1.15 & 1.95 & 2.37 \\
Sulphate (mg/L) & n.a & n.a & n.a & 27.6 \\
Iron (mg/L) & 3.06 & 0.17 & 1.13 & 0.968 \\
Copper (mg/L) & 0.4 & 0.03 & 0.13 & 0.312 \\
Zinc (mg/L) & 0.74 & 0.03 & 0.16 & 0.315 \\
TSS (mg/L) & n.a & n.a & n.a & 347 \\
\hline n.a : not available/not measured & & & &
\end{tabular}

The observed data was obtained from field measurement on November 2010 at the Glenroy sewer branch. The simulated flow is lower compared to the average value of the observed flow. However, all the simulated values are in the range of max-min of the observed values. The flow and concentration difference might come from the different time allocation where UVQ gives the annual average flow and concentration, whereas the observed value was obtained on November, 2010. Moreover, during November of 2010, the 
number of rainy days was more than the dry days which means that a lot of inflow and infiltration from surface water to the sewerage pipe network. This reason justify why the observed flow is quite high compared to the simulated value.

\section{ANALYSIS \& RESULTS}

\subsection{Annual Performance}

UVQ uses several measures of performance; number of event failures, deficit and annual volumetric reliability. In the case of event failure, an inability to provide anything but all of the demand in a time step is considered as a failure, reducing the storage's overall reliability. The deficit of a store is the shortfall of water in $\mathrm{m} 3$ when compared to demand (performance for all scenario see Table 3).

Table 3. Annual Performance of Greywater Direct Diversion, Greywater Recycling, Rainwater Harvesting and Sewer Mining

\begin{tabular}{lcccc}
\hline & Greywater Direct Div. & Greywater Recycling & Rainwater Harvesting & Sewer Mining \\
\hline Demand for greywater, Ml & 76 & 165 & 79 & 79 \\
Supply of greywater, Ml & 291 & 291 & 73 & 405 \\
Use of greywater, Ml & 75 & 151 & 6 & 79 \\
Deficit of greywater, Ml & 0.7 & 13 & 50 & 0 \\
Spillage of greywater, Ml & 216 & 22 & 26 & 331 \\
No. of event failure, days & 4 & 94 & 93 & 0 \\
Annual Reliability, \% & 99 & & 100 & \\
\hline
\end{tabular}

\subsection{Wastewater Flows and Contaminant}

From Table 4, it can be seen that all the wastewater flow were much lower than the base case. The highest wastewater reduction is obtained by high water demand management scenario, and then followed by greywater recycling, sewer mining, greywater direct diversion and rainwater harvesting, respectively. The wastewater reduction due to rainwater harvesting is not significant because in this scenario, there is no reduction in water consumption or diversion of wastewater. The contaminants load in SMPs scenarios does not exhibit much difference with the base case scenario. The exception is showed in iron load where the rainwater harvesting scenario has much higher load when compared to the base case. Iron concentration highly increase in rainwater harvesting because the roof runoff contains high iron concentration. This runoff is collected in rainwater tank then used for toilet flushing which eventually flowed to sewerage network.

Table 4. Wastewater Flow and Contaminant Load

\begin{tabular}{|c|c|c|c|c|c|c|c|c|}
\hline & $\begin{array}{l}\text { Flow } \\
\text { Ml/yr }\end{array}$ & $\begin{array}{c}\text { COD } \\
\mathbf{t} / \mathbf{y r}\end{array}$ & $\begin{array}{c}\text { Nitrate } \\
\mathbf{t} / \mathbf{y r}\end{array}$ & $\begin{array}{c}\text { Sulphate } \\
\text { t/yr }\end{array}$ & $\begin{array}{l}\text { Iron } \\
\text { t/yr }\end{array}$ & $\begin{array}{c}\text { Copper } \\
\text { t/yr }\end{array}$ & $\begin{array}{c}\text { Zinc } \\
\text { t/yr }\end{array}$ & $\begin{array}{l}\text { TSS } \\
\text { t/yr }\end{array}$ \\
\hline Base Case & 410 & 216 & 0.97 & 11.2 & 0.397 & 0.128 & 0.129 & 142 \\
\hline High Water Demand Mngmt. & 232 & 216 & 0.62 & 10.9 & 0.385 & 0.089 & 0.11 & 142 \\
\hline Greywater Direct Diversion & 338 & 186 & 0.8 & 8.3 & 0.151 & 0.106 & 0.063 & 136 \\
\hline Greywater Recycling & 263 & 190 & 0.74 & 7.7 & 0.128 & 0.103 & 0.053 & 140 \\
\hline Rainwater Harvesting & 408 & 220 & 0.83 & 11.6 & 0.479 & 0.114 & 0.144 & 142 \\
\hline Sewer mining & 331 & 205 & 0.74 & 7.2 & 0.363 & 0.105 & 0.102 & 138 \\
\hline
\end{tabular}

Table 5. Contaminant Concentration

\begin{tabular}{lccccccc} 
& $\begin{array}{c}\text { COD } \\
\mathbf{m g} / \mathbf{l}\end{array}$ & $\begin{array}{c}\text { Nitrate } \\
\mathbf{m g} / \mathbf{l}\end{array}$ & $\begin{array}{c}\text { Sulphate } \\
\mathbf{m g} / \mathbf{l}\end{array}$ & $\begin{array}{c}\text { Iron } \\
\mathbf{m g} / \mathbf{l}\end{array}$ & $\begin{array}{c}\text { Copper } \\
\mathbf{m g} / \mathbf{l}\end{array}$ & $\begin{array}{c}\text { Zinc } \\
\mathbf{m g} / \mathbf{l}\end{array}$ & $\begin{array}{c}\text { TSS } \\
\mathbf{m g} / \mathbf{l}\end{array}$ \\
\hline Base Case & 527 & 2.37 & 27.6 & 0.97 & 0.312 & 0.315 \\
High Water Demand Mngmt. & 931 & 2.67 & 47.2 & 1.66 & 0.385 & 0.475 \\
Greywater Direct Diversion & 551 & 2.33 & 24.4 & 0.45 & 0.312 & 0.188 \\
Greywater Recycling & 602 & 0.62 & 21.9 & 0.28 & 0.122 & 0.093 & 401 \\
Rainwater Harvesting & 539 & 2.03 & 28.4 & 1.17 & 0.278 & 0.352 \\
Sewer mining & 618 & 2.2 & 21.6 & 1.1 & 0.3 & 0.3 \\
\hline
\end{tabular}

Table 5 shows that highest increase in contaminant concentration is achieved by high water demand management because the wastewater discharge to sewerage network are reduced much and the contaminant load are relatively same with the base case. All the scenarios increase their COD and TSS concentration but for other contaminants the concentration varies. 


\section{DISCUSSION AND CONCLUSION}

According to the water and wastewater balance modeling, the SMPs implementation has been proved to reduce wastewater flow and change contaminant characteristics. These wastewater characteristics changes are likely to affect the physical and biochemical processes in sewerage pipe networks. In this study, the preliminary analysis on wastewater characteristics that determine the presence of odour and corrosion problem in sewer network has been conducted.

From section 2, it was clear that the increasing or decreasing problem of odour and corrosion can be indicated from the wastewater characteristics discharges to sewerage network. High organic, sulphate and solid concentration as well as less wastewater flow would be the supporting wastewater characteristics to exacerbate the current problem of odour and condition. In other hand, high nitrate and metal (iron, copper and zinc) concentration would give reverse impact on sewerage network because the presence of these chemical are able to alleviate odour and corrosion. It has been shown in this study that the sewer mining, high water demand management, greywater recycling and greywater direct reuse are some of the SMPs that potentially exacerbate the sewer condition since they either reduce the wastewater flow or increase the COD and TSS load which eventually increase the contaminant concentration that cause odour and corrosion in sewerage network. However, the scenario of rainwater harvesting would potentially alleviate the sewer problem since the metal concentration especially iron and zinc have increased in wastewater contaminant. The uncertainty analysis which is part of precision and accuracy of the model will be conducted in the future. To know the definite impact of SMPs in sewerage networks, further research on sewerage network modeling need to be conducted. The simulation results from water and wastewater balance modeling can be used as one of the inputs in sewer modeling.

\section{REFERENCES}

Almeida, MC, Butler, D \& Friedler, E (1999), At-source domestic wastewater quality, Urban Water, Vol. 1, No. 1, pp. 49-55.

Australian Government (2010a), National Rainwater and Greywater Initiative, Canberra, $<$ http://www.environment.gov.au/water/programs/nrgi/>.

Australian Government (2010b), Water Efficiency Labelling and Standards (WELS) Scheme, 30 June 2010, $<\underline{\text { http://www.waterrating.gov.au/consumers/index.html }>\text {. }}$

Cook, S, Tjandraatmadja, G \& Marleni, N (2010), Impact of source management strategies on quality and loads in residential wastewater-scenario analysis, CSIRO : Water for a Healthy Country National Research Flagship, Melbourne.

Coombes, PJ, Kuczera, G \& Kalma, JD (2002), Rainwater quality from roofs, tanks and hot water systems at Figtree place, in 3rd International Hydrological and Water Resources Symposium, Perth, Australia.

Eriksson, E, Auffarth, K, Henze, M \& Ledin, A (2002), Characteristics of grey wastewater, Urban Water, Vol. 4, No. 1, pp. 85-104.

Mitchell, VG \& Diaper, C (2005), Draft UVQ User Manual, CSIRO, Melbourne.

Nielsen, AH, Lens, P, Vollertsen, J \& Hvitved-Jacobsen, T (2005), Sulfide-iron interactions in domestic wastewater from a gravity sewer, Water Research, Vol. 39, No. 12, pp. 2747-55.

Parkinson, J, Schutze, M \& Butler, D (2005), Modelling the impacts of domestic water conservation on the sustainability of the urban sewerage system, Journal of the Chartered Institution of Water and Environmental Management, Vol. 19, No. 1, pp. 49-56.

Radcliffe, J (2010), Evolution of water recycling in Australian cities since 2003, Water Science and Technology, Vol. 62, No. 4, pp. 792-802.

Roberts, P (2005), Yarra Valley Water 2004 Residential End Use Measurement Study, Yarra Valley Water, Melbourne.

Surendran, S \& Wheatley, A (1998), Grey Water Reclamation for Non Potable Re Use, Water and Environment Journal, Vol. 12, No. 6, pp. 406-13.

Tchobanoglous, G, Burton, FL \& Stensel, HD (2003), Wastewater engineering: treatment and reuse, McGraw-Hill Science/Engineering/Math.

Yaziz, MI, Gunting, H, Sapari, N \& Ghazali, AW (1989), Variations in rainwater quality from roof catchments, Water Research, Vol. 23, No. 6, pp. 761-5.

YVW (2010), Information provided by Yarra Valley Water.

Zhang, LH, De Schryver, P, De Gusseme, B, De Muynck, W, Boon, N \& Verstraete, W (2008), Chemical and biological technologies for hydrogen sulfide emission control in sewer systems: a review, Water Research, Vol. 42, No. 1-2, pp. 1-12. 